\title{
Using Songs Effectively to Teach English to Young Learners
}

\author{
Neil T. Millington \\ Ritsumeikan Asia Pacific University, Japan
}

\begin{abstract}
Songs play an important role in the development of young children learning a second language. A testament to this is the frequency with which songs are used in English Language Teaching classrooms all over the world. This paper begins by looking at why songs can be considered valuable pedagogical tools. In particular, it will discuss how songs can help learners improve their listening skills and pronunciation, and how they can be useful in the teaching of vocabulary and sentence structures. The author will also discuss how songs can reflect culture and increase students' overall enjoyment of learning a second language. The author will then attempt to show, through practical examples, how songs can be used as language tasks. Finally, the paper aims to explore how classic songs for children can be adapted to suit a particular theme or part of the curriculum a teacher might wish to teach.
\end{abstract}

Most children enjoy singing songs, and they can often be a welcome change from the routine of learning a foreign language. For the teacher, using songs in the classroom can also be a nice break from following a set curriculum. Songs can be taught to any number of students and even those teachers with the most limited resources can use them effectively. Songs can play an important role in the development of language in young children learning a second language. Yet songs may be used relatively ineffectively and the potential for language learning is not maximized.

This paper starts by analyzing why songs should be considered as useful pedagogical tools. The author then proposes using songs as language learning tasks to maximize the benefits of using songs and attempts to show how this might be done using practical examples. Finally, the paper explores how classic children's songs could be modified to help teachers use them more frequently to teach a wider variety of topics.

\section{Songs as Pedagogical Tools}

One advantage of using songs in the young learner classroom is their flexibility. Songs can be used for a number of purposes and there are many reasons why songs can be considered a valuable pedagogical tool. Songs can help young learners improve their listening skills and pronunciation, therefore potentially helping them to improve their speaking skills (Murphey, 1992). Songs can also be useful tools in the learning of vocabulary, sentence structures, and sentence patterns, not to mention their reflectivity of mother tongue culture (Murphey, 1992). Perhaps the greatest benefit to using songs in the classroom is that they can be fun. Pleasure for its own sake is an important part of learning a language, something which is often 
overlooked by teachers, and songs can add interest to the classroom routine and potentially improve student motivation.

Listening. Purcell (1992) states that students can become bored by repeatedly listening to a narration or dialog as they attempt to understand the meaning of new words or phrases in context. In contrast, listening to a song over and over again can seem less monotonous because of the rhythm and melody. Some songs, such as Hello, contain common expressions and can be used as good listening activities. For example, the teacher could sing the first three lines of the song below, and students could respond with the following three lines.

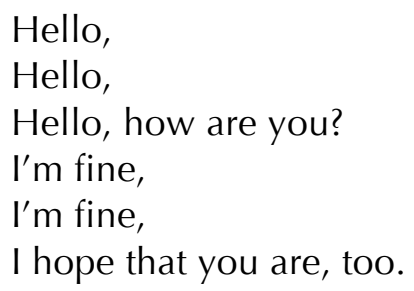

Songs can also help to improve listening skills because they provide students with practice listening to different forms of intonation and rhythm. English has a stress-timed rhythm, for which songs can help to establish a feeling. Murphey believes that music has the power to engrave itself into our brains, stating that "songs work on our short- and long-term memory" and are therefore adequate tools for using in the language classroom (1992, p. 3).

Speaking. Children are often keen to learn how to make new sounds and this can take a great deal of practice. Some teachers use minimal-pair drills, yet these types of activities are rarely interesting for young learners. Songs, on the other hand, can allow young learners to practice a new sound without producing the same level of boredom. Songs also have a natural rhythm with a recurring beat that is similar to the stress patterns of spoken English. These patterns make some songs useful for practicing rhythm and stress. The song Girls and Boys Come Out and Play could be used effectively to teach English rhythm and stress, for example (Richards, 1969, p. 162).

Girls and boys come out to play, The sun above is bright today. Leave your work and leave your sleep, Come and join us in the street. Come with a shout and come with a call, Come with a smile and bring your ball. Down the steps and up the path, All the fun will make you laugh.

Moriya (1988) emphasizes the value of using songs for pronunciation practice with Asian learners of English due to the phonemic differences between Asian languages and English. For example, there are several problematic areas for Japanese students learning English. Ohata (2004) shows the differences in vowels, consonants and syllable types that cause difficulties for Japanese learners of English. Practicing the different sounds by singing songs can be more interesting and enjoyable than other activities such as minimal-pair drills.

Vocabulary. Songs can provide the opportunity for vocabulary practice. They are usually based around a theme or topic that can provide the context for vocabulary learning. The song 
Head, Shoulders, Knees and Toes, for example, could be used to review body parts, or the song I Can Sing a Rainbow might be useful for reviewing color names. Most children's songs are characterized by monosyllabic words, many of which are frequently repeated. This repetition offers greater exposure to these words and can help to improve vocabulary acquisition.

Some of the vocabulary and language used in traditional and popular English songs, however, can cause difficulties for language learners due to their use of low frequency and archaic words. The song and the lyrics need to be selected carefully to complement the target vocabulary. A difficulty for teachers is finding and selecting songs that are suitable both in terms of vocabulary and topic or theme.

Sentence structures and sentence patterns. Many children's songs have a simple sentence structure or sentence pattern that can become set in the mind of the learner. Songs could be used to reinforce questions taught in the classroom. The songs Where is Thumbkin?, Hello, What's Your Name?, and Who is Wearing Red? might be useful for practicing WH-question forms, for example. Websites such as The Teacher's Guide (http://www.theteachersguide. com/) or NIEHS Kids' Pages (http://kids.niehs.nih.gov/) provide hundreds of children's songs with lyrics for teachers to use.

The length of a phrase in a typical children's song is short and often uses simple conversational language. Murphey (1992) states that the pauses after each phrase are typically longer in comparison to the phrase itself, which can allow learners to process the language and shadow in real time. Again though, the teacher needs to take care when selecting a song because some songs have irregular sentence structures that are not typically used in English conversation.

Culture. According to Jolly (1975), using songs can also give learners the opportunity to acquire a better understanding of the culture of the target language. Songs reflect culture; Shen states, "language and music are interwoven in songs to communicate cultural reality in a very unique way" (2009, p. 88). Although this is probably more applicable to songs for older learners, young learners can be given the opportunity to learn about seasonal or historical events in the target language through songs.

Enjoyment. Probably the most obvious advantage to using songs in the young learner classroom is that they are enjoyable. Most children enjoy singing and usually respond well to using songs in the classroom, but there are more significant benefits to using songs other than just being fun. First, songs can bring variety to the everyday classroom routine. This variety stimulates interest and attention, which can help maintain classroom motivation, thereby helping learners to reach higher levels of achievement. Secondly, songs, in particular choral singing, can help to create a relaxed and informal atmosphere that makes the classroom a nonthreatening environment. By reducing anxiety, songs can help increase student interest and motivate them to learn the target language. Students often think of songs as entertainment rather than study and therefore find learning English through songs fun and enjoyable.

Limitations. Although there are many reasons why songs can be considered a valuable teaching tool, there are some issues to consider. As mentioned above, the teacher needs to take care in selecting a suitable song for his or her class. The language, vocabulary, and sentence structure of some songs can be quite different from that used in spoken English (Richards, 1969, p. 163). For example, the children's song or nursery rhyme, Jack Be Nimble, is not likely to help the learner in the use of the be verb: 
Jack be nimble, Jack be quick,

Jack jump over the candlestick.

In addition, there are other difficulties placed on the teacher. To maintain variety in the classroom, the teacher needs a good repertoire of songs. Although young learners are happy to sing the same song on several occasions, interest in the same song can soon fade if the song is used too often. Some non-native English-speaking teachers may also worry about teaching the stress and timing of songs correctly, and are therefore probably more likely to only use certain songs that they feel comfortable with. Finally, Murphey (1992) points out that no matter how enjoyable or memorable, singing songs in itself will not teach anyone to use the language, and will not give students the ability to communicate in another language. The words in songs unfortunately do not transfer into use.

\section{Songs as Tasks}

One way to maximize the advantages and minimize some of the limitations mentioned above might be to develop songs into language learning tasks. Although this alone will not help teachers develop a greater repertoire of songs, it can help turn a song into a useful tool for language learning and teaching (Cameron, 2001, p. 31).

\section{Defining a Task}

Cameron defines an activity for young learners as "any kind of event that children participate in" (2001, p. 31), but adds, not all classroom activities can be classified as tasks. For an activity to be considered a task, it must have more carefully planned and structured events with learner participation as the fulcrum (Cameron, 1997, p. 346). Cameron provides "a list of defining features of task for use in teaching foreign languages to children" (2001, p. 31).

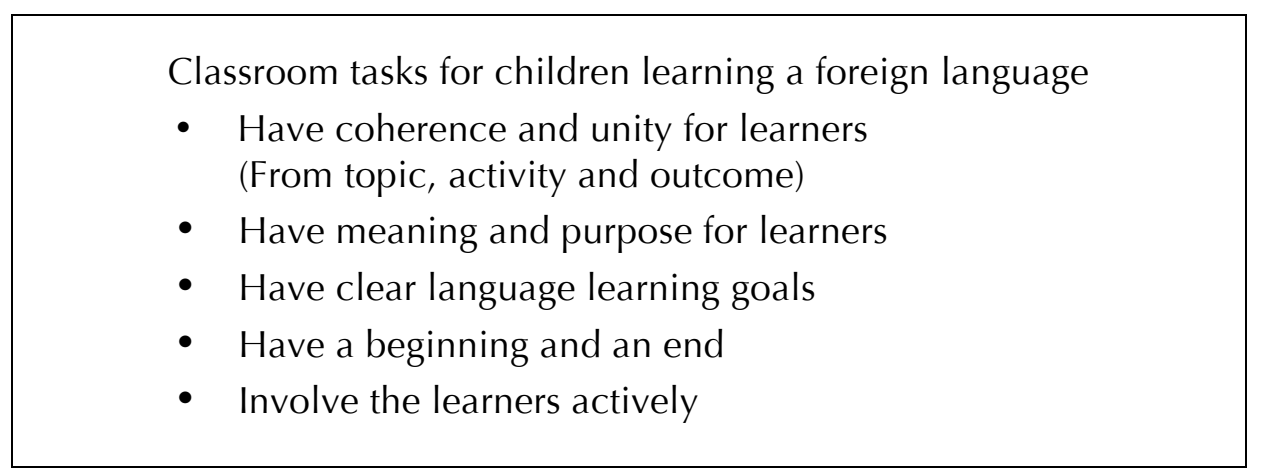

Figure 1. Classroom tasks for children learning a foreign language from Cameron, 2001, p. 31.

These defining features benefit the teacher because they provide a reference point when planning a lesson or analyzing a lesson plan; for researchers, it "provides a unit around which to develop an understanding of language learning and teaching processes" (Cameron, 1997, p. 346). In addition to these five features, Cameron (2001) reports that tasks for young learners should have three stages: preparation, core activity and follow up.

\section{Developing a Song into a Task}

The Wheels on the Bus, a popular children's song often sung by children in the U.K., U.S., and Canada, is used here to illustrate how a song could be developed into a language learning task. 
The wheels on the bus go round and round,

round and round,

round and round.

The wheels on the bus go round and round,

all day long.

Figure 2. The lyrics to the first stanza of The Wheels on the Bus

There are several reasons why this particular song might be suitable for language learning purposes. The lyrics of the song are made up of 11 monosyllabic words, many of which are repeated several times. The phrases are short with relatively long pauses between each one and are comprised of simple vocabulary. The song also has a repetitive rhythm with a recurring beat that is similar to the stress patterns of spoken English.

\section{The Three Stages of a Song as a Task}

Cameron (1997, p. 347) states that classroom tasks for young learners have three stages that "once identified, can be analyzed, adapted, and expanded" and notes that "it has been common practice for many years to plan reading activities in three stages: pre-reading, reading and post-reading" (2001, p. 32). Cameron adds that this has been adapted for mainstream task-based learning by Skehan (1996, cited in Cameron, 2001) and adopts it herself with the following labels (Cameron, 2001):

\section{PREPARATION $\longrightarrow$ CORE ACTIVITY $\longrightarrow$ FOLLOW UP}

Figure 3. Three Stages in "Task" for Young Learners from Cameron (2001, p. 32)

Cameron argues that the core activity is central to the language learning task and without the core, the task would collapse. The preparation activities should help to prepare the students to complete the core activity successfully. This might include pre-teaching of language items or activating topic vocabulary. The follow-up stage then should build on the completion of the core activity (2001, p. 32).

Preparation stage. Given the goal of the task is singing the song in the core activity stage, it is useful to activate the vocabulary and to form basic sentence structures in the preparation stage. This could be done using a number of methods, depending on the resources available to the teacher or the size of class. One way of activating vocabulary might be to use a picture of a bus to elicit vocabulary and form basic sentence patterns. For example, the teacher pointing to the bus driver could ask, "Who is he?" Students reply, "A bus driver." The teacher then asks, "What does the bus driver do?" Students reply, "The bus driver drives the bus." The teacher might then point to the wheels and ask, "What are they?" Students reply, "They are wheels." The teacher then could ask, "What do the wheels do?" The students are encouraged to reply, "The wheels go round." Of course this is only one option; the teacher may not have access to images to match the song and might want to ask the students to draw a picture. The pictures could be used to elicit vocabulary and practice the sentence structures used in the song. Regardless of how the teacher chooses to activate vocabulary and form sentence structures, the 
aim is that, at the end of the preparation stage, the students are ready to sing the song in the core stage.

Core stage. To involve the students and maximize interest, it would be advantageous to sing the song several times in the core, each time varying the pace or volume and having the students perform actions and sing along chorally. For example, the teacher could begin by asking the students to sing the word wheels at first, and have the students make a circle shape with their hands. Then the teacher could have the students turn around 360 degrees when singing round and round.

Follow-up stage. The follow-up stage should attempt to build on the successful completion of the core stage. In other words, the students have sung the song and now should be encouraged to use the vocabulary or sentence structures from the song. Again, this depends on the circumstances of the teacher. The follow-up stage could be used to develop written production, either through writing sentences or gap-fill activities, or oral production where the vocabulary learned is used in a situational role-play.

\section{Maximizing the Potential of Songs}

Using songs as language learning tasks can help to maximize the potential of songs as teaching and language learning tools. As stated above, there are benefits to using songs in the classroom; however, more often than not, songs are used relatively ineffectively, often as activities between learning. It was stated above that no matter how enjoyable or memorable singing songs can be, singing songs in itself will not teach learners to use the language and will not give them the ability to communicate in another language. However, developing a song from an activity into a task with preparation, core, and follow-up stages might be one way to help transfer the words in a song into use and maximize the potential of songs as teaching and learning tools.

\section{Creating Original Songs}

There are thousands of children's songs; selecting, learning, and using a suitable song for a particular class or purpose can be a real challenge for language teachers. Some teachers do not have a huge repertoire of songs and therefore tend to sing the same set of songs or avoid using songs completely. It can also be challenging to select a song to fit in with the curriculum or language point to be taught. As mentioned above, care needs to be taken when selecting a song because the vocabulary and sentence structure of some children's songs can be quite different from that used in spoken English.

With a little initiative and imagination, a children's song can easily be adapted. By slightly altering the vocabulary, grammar, or sentence structure whilst maintaining the original rhythm, a traditional song can be adapted to suit a particular theme or part of the curriculum. Below is an example that illustrates how this may be done. The song, The Wheels on the Bus (see Figure 2), requires only minor adaptations to make it more suitable for teaching a different topic; in this example, it becomes a song about sea creatures. 
The fish in the sea goes swim, swim, swim, swim, swim, swim, swim, swim, swim.

The fish in the sea goes swim, swim, swim, all day long.

The lobster in the sea goes pinch, pinch, pinch, pinch, pinch, pinch, pinch, pinch, pinch.

The lobster in the sea goes pinch, pinch, pinch, all day long.

The crab in the sea goes click, click, click,

$$
\begin{aligned}
& \text { click, click, click, } \\
& \text { click, click, click. }
\end{aligned}
$$

The crab in the sea goes click, click, click, all day long.

The octopus in the sea goes wiggle, wiggle, wiggle,

$$
\begin{aligned}
& \text { wiggle, wiggle, wiggle, } \\
& \text { wiggle, wiggle, wiggle. }
\end{aligned}
$$

The octopus in the sea goes wiggle, wiggle, wiggle,

all day long.

Figure 4. The modified lyrics from the song The Wheels on the Bus (adaptations bolded)

By adapting the song in this way, the teacher has the advantage of being able to select a particular language feature and incorporate it into the song. This feature could be an item of vocabulary, syntax, phonology, or a simple conversational expression. This allows the teacher to incorporate more songs into a curriculum and save time searching for and learning new songs.

\section{Conclusion}

The first purpose in presenting this paper is to state a case for developing songs from activities into language learning tasks. The second purpose is to highlight how, with a little initiative, teachers can adapt children's songs to better suit their teaching goals. Songs can be used as a valuable teaching and learning tool. Using songs can help learners improve their listening skills and pronunciation; they can also be useful for teaching vocabulary and sentence structures. Probably the greatest benefit to using songs in the classroom is that they are enjoyable. Unfortunately, despite these advantages, simply singing songs will not teach learners how to communicate in another language. Using songs as tasks might be one way of helping transfer words from songs into use, and maximize the potential of songs as teaching and learning tools. Adapting existing children's songs is one method that teachers can use to increase their repertoire of songs, thus giving them more opportunity to use songs in their teaching contexts. 


\section{Author Note}

Neil T. Millington, Center for Language Education, Ritsumeikan Asia Pacific University, Japan.

Many thanks to Ro Nagji for his informative ideas on creating original songs for children and to Brad Smith for his help editing this paper.

Correspondence concerning this article should be addressed to Neil T. Millington, Center for Language Education (CLE), Ritsumeikan Asia Pacific University, 1-1 Jumonjibaru, Beppu-Shi, Oita, Japan 874-8577. E-mail: millingt@apu.ac.jp

\section{References}

Cameron, L. (1997). The task as a unit for teacher development. ELT Journal, 51(4), 345-351. http://dx.doi.org/10.1093/elt/51.4.345

Cameron, L. (2001). Teaching languages to young learners. Cambridge, England: Cambridge University Press.

Jolly, Y. S. (1975). The use of songs in teaching foreign languages. The Modern Language Journal, 59(1/2), 11-14.

Moriya, Y. (1988). English speech rhythm and its teaching to non-native speakers. Paper presented at the annual convention of Teachers of English to Speakers of Other Languages, Chicago.

Murphey, T. (1992). Music and Song. Oxford, England: Oxford University Press.

NIEHS Kids' Pages. (2010). Retrieved from http://kids.niehs.nih.gov/

Ohata, K. (2004). Phonological differences between Japanese and English: Several potentially problematic areas of pronunciation for Japanese ESL/EFL learners. Asian EFL Journal, 6(4). Retrieved from http://www.asian-efl-journal.com/december_04_KO.php

Purcell, J. M. (1992). Using songs to enrich the secondary class. Hispania, 75(1), 192-196. Retrieved from http://www.jstor.org/stable/344779

Richards, J. (1969). Songs in language learning. TESOL Quarterly, 3(2), 161-174.

Shen, C. (2009). Using English songs: An enjoyable and effective approach to ELT. English Language Teaching, 2(1), 88-94. Retrieved from www.ccsenet.org/journal.html

The Teacher's Guide. (n.d.). Retrieved from http://www.theteachersguide.com/ 